\title{
Seroprevalence and the associated risk factors of Toxoplasma gondii infection among pregnant women in the middle belt of Ghana
}

\section{DERRICK ADU MENSAH}

Kwame Nkrumah University of Science and Technology School of Medical Sciences

https://orcid.org/0000-0002-8972-1757

\section{Linda Batsa Debrah}

Kwame Nkrumah University of science and technology school of medicine and dentistry

\section{Clement Evans Aryee}

Goaso Municipal Hospital, Goaso.

ALEXANDER YAW YAW DEBRAH ( $\nabla$ yadebrah@yahoo.com )

\section{Research article}

Keywords: Seroprevalence, Toxoplasma gondii, Toxoplasmosis, Pregnant women, Anti-T. gondii IgG, Anti

T. gondii IgM

Posted Date: July 30th, 2019

DOI: https://doi.org/10.21203/rs.2.12162/v1

License: (9) (i) This work is licensed under a Creative Commons Attribution 4.0 International License.

Read Full License 


\section{Abstract}

Background Exposure to Toxoplasma gondii infection is prevalent in up to $90 \%$ of the world's population. Severe infections can be fatal and deforming in neonates. Cats serve as reservoirs for T. gondii infections. Even though many Ghanaians have cats as pets in their homes only few studies have been undertaken to assess the prevalence of the disease in Ghana. The objective of the study was to determine the seroprevalence of T. gondii infection and its associated risk factors among pregnant women seeking antenatal care at the Goaso Municipal Hospital, in Asunafo North District of the Ahafo Region and the St. Michael's Catholic Mission Hospital in the Bosomtwe District in the Ashanti Region of Ghana. Methods A cross-sectional study involving 266 (146 from Asunafo North District and 120 from Bosomtwe District) pregnant women who consented to participate in the study was undertaken. To gather information on associated risk factors, structured questionnaire was administered to the participants. In addition, 3 mls of venous blood was collected from each participant for anti-T. gondii IgG and anti-T. gondii IgM antibody analyses using ELISA. Results A total of $64.3 \%(171 / 266)$ of the study participant were positive for anti-T. gondii IgG and $26.3 \%$ (70/266) were positive for anti-T. gondii IgM antibodies. This signifies that $64.3 \%$ of the study population have been exposed to the infection and $26.3 \%$ were actively infected. There were no differences $(P=0.383)$ between the overall T. gondii seroprevalences in the two Districts. There was a significant difference between antibody concentration levels and age in the Bosomtwe District in Ashanti Region. No association $(\mathrm{OR}<1)$ was found between the seroprevalences and the suspected risk factors assessed in this study. Conclusion The study showed that the seroprevalence of T. gondii among pregnant women visiting the two health facilities in the two Regions was higher compared to the $30 \%-65 \%$ reported as the global population infection status. This study provides baseline data for future studies in the other Districts and Regions in the country to ascertain the overall seroprevalence in Ghana.

\section{Background}

Toxoplasma gondii is a protozoan parasite that affects primarily members of the felid family but also most genera of warm-blooded animals, including birds and humans. It causes the disease toxoplasmosis [1-2]. Toxoplasma gondii is an obligate intracellular coccidian parasite that typically requires alternation of sexual and asexual reproductive stages in their life cycle [3-4]. Toxoplasmosis infection in its severest form can be fatal in neonates and in the immunocompromised such as HIV patients and patients who have undergone organ transplantation or immunosuppressive therapies [5].

The parasite exists in three main morphological forms; the first being the infective oocysts which release sporozoites extracellularly, the second is the trophozoite stage which is responsible for intracellular invasion and lastly the tissue cysts stage, which is either actively dividing (tachyzoites) or slowly dividing (bradyzoites) [6-8]. T. gondii infections in humans occur through the ingestion of tissue cysts in poorly cooked meat, transplancental (vertical) transmission from mother to foetus in-utero and rarely through organ transplantation and blood transfusion from seropositive donors [9-10]. 
About $20 \%$ to $90 \%$ of the world's adult population in different regions are reported to have had contact with the parasite [9], with about $15 \%$ of women of childbearing age being immune to toxoplasmosis [11]. Although pregnant women are not classified as being immunosuppressed, changes in their immune system may illicit an increment in the state of their susceptibility to certain intracellular pathogenic agents [12]. Women infected with $T$. gondii infection before being pregnant rarely transmit the infection to their foetuses. Unfortunately, women infected with $T$. gondii during pregnancy can transmit the infection across the placenta to their foetuses. The undeveloped immune system of foetuses make them highly vulnerable when their mothers become infected for the first time during pregnancy [13]. Research has shown that the risk of congenital transmission with acute maternal infection in the first trimester is the lowest (10-15\%), with a maternal infection in the third trimester having the highest risk (68\%) [14-15]. However, a first trimester acquisition of the disease is the most severe [16].

Infection acquired during the first trimester may lead to spontaneous abortion, still births, mental retardation, hepatosplenomegaly, jaundice, chorioretinitis, hydrocephalus, convulsions, intracerebral calcifications and other disseminated infections, while infection acquired later during pregnancy is usually asymptomatic and sub-clinical in the neonate $[12,17-18]$. Hydrocephalus is the least common but most dramatic lesion of congenital toxoplasmosis. Ocular disease is the most common sequelae of toxoplasmosis [19].

Studies on seroprevalence of toxoplasmosis in the middle belt of Ghana is scarce. Studies on the infection have however been conducted in Southern part of the country [4, 20-21]. A seroprevalence of $76.0 \%$ of the anti-Toxoplasma antibodies was reported among pregnant women in Mamprobi Clinic in Accra, Ghana. Other similar studies in the Greater Accra Region reported overall seroprevalences which ranged from $29.7 \%$ to $92.5 \%$ [4, 20-21]. Since many households in the middle belt of Ghana own pets which serve as reservoirs for $T$. gondii, there is the need to assess the prevalence in the middle belt.

This study therefore, sought to determine the seroprevalence of T. gondii infection and its associated risk factors among pregnant women seeking antenatal care (ANC) at the Municipal Hospital Goaso, in the Asunafo North District of the Ahafo Region and St. Michael's Catholic Mission Hospital at Pramso in the Bosomtwe District; Ashanti Region, Ghana.

\section{Methods}

\section{Study area}

The antenatal clinic at the Municipal Hospital, Goaso in the Asunafo North district of the Ahafo Region and the St. Michael's Catholic Mission Hospital at Pramso in the Bosomtwe District, Ashanti Region Ghana were selected for the study due to their respective geographic locations and large population numbers as well as being sub-district referral health centres'. 


\section{Ethical Considerations}

Ethical approval was obtained from the Committee on Human Research, Publications and Ethics (CHRPE), of the School of Medicine and Dentistry of the Kwame Nkrumah University of Science and Technology, Kumasi. Informed consent, either signed or thumbed, was obtained from every participant before enrolling them in this study. Additional consent, either signed or thumbed, was obtained from parents or guardians of participants who were below 18 years. Further permission was sought from the appropriate hospital authorities and institutions.

\section{Study design}

About $3 \mathrm{mls}$ of venous blood was collected from each participating pregnant woman into a gel clot activated tubes. One milliliter of serum was collected from the whole blood samples after centrifuging at $2000 \mathrm{~g}$ for 10 minutes and preserved at $-20^{\circ} \mathrm{C}$ for later serological analysis. The samples were analysed quantitatively for the presence of anti-T. gondii IgG which depicts previous or past exposure to the infection and anti-T. gondii IgM antibodies denoting current or present infection using a commercially produced ELISA kit (RecombiLISA Toxo Test Kit (Fortress Diagnostics Limited, unit 2C Antrim Technology Park, BT41 1QS, UK) in accordance with manufacturer's instructions. Close-ended questionnaires were administered by the interviewer to gather demographic information on the study participants as well as their exposure to the various risk factors.

\section{Recruitment of study participants}

The recruitment involved 146 pregnant women aged between 16 to 40 years seeking antenatal care in the Asunafo North District and 120 from the Bosomtwe District. The participating pregnant women had to meet the exclusion and inclusion criteria by not being anaemic $(\mathrm{Hb}>8.0 \mathrm{~g} / \mathrm{dl})$, should be living in the respective region and should have consented to be considered for the study.

\section{Data analysis}

Descriptive statistical analysis of the seroprevalence of the $T$. gondii infection and the associations between the responses to relevant questions on exposure to the infection risk factors and infection status were determined by the level of statistical significance at a confidence interval of $95 \%$ using SPSS (Statistical Package for Social Scientists) version 24, Graph Pad Prism software and Microsoft Excel. Demographic data were collated into a Microsoft excel sheet. Analysis of variance (ANOVA) was performed using SPSS version 24 to test for differences between means. Two-tailed unpaired t-tests were performed using the GraphPad Prism version 6.02. P-values less than 0.05 was considered significant. Correlative associations between the various suspected risk factors assessed and seroprevalences were also determined using the odds ratio statistical tool from the SPSS version 24. 


\section{Results}

There was even distribution of study participants in the various age groups in the two study districts (Table 1). A mean age of 27.3 years was recorded for the participants from Asunafo North and 28.0 years for the Bosomtwe District. Comparing the ages of participants in the two districts, there was no statistical difference $(P>0.05)$.The number of study participants increased with age until age 25 years after which there was a gradual decrease up to 40years (Table 1).

The number of participants in the second trimester in Asunafo North District were more than the first and the third trimester. However it was not statistically different from the number of participants in the second trimester in Bosomtwe District $(P=0.066)$. None of the participants had ever been screened for $T$. gondii infection in both Districts prior to the commencement of the study. (Table 1).

Table 1: Age and stage of pregnancy distribution of study participants in the two Districts

The study revealed that $64.3 \%(171 / 266)$ and $26.3 \%$ (70/266) of the study participants were seropositive for IgG and IgM respectively. Also, 23.3\% (34/146) of the participants in the Asunafo North District and $30 \%(36 / 120)$ of participants from Bosomtwe District were seropositive for anti-T. gondii IgM where as $67.8 \%(99 / 146)$ and $60 \%(72 / 120)$ were seropositive for anti-T. gondii IgG in the two districts respectively. Significant differences were recorded between the IgG and IgM seroprevalence in both Districts $(P<0.001)$.

Most of the participants in the Asunafo North District had significantly been exposed previously to toxoplasmosis as compared to those in the Bosomtwe District $(P=0.037)$. However, considering their current infection status $(\mathrm{IgM})$, there was no significant difference $(\mathrm{P}=0.069)$. The total anti-T. gondii antibody seroprevalence was 78.1\% (114/146) and 75\% (90/120) respectively in the Asunafo North and Bosomtwe Districts and the difference was statistically not significant $(P=0.383)$.

There was an increase in the seropositivities of both IgM and IgG from age 16 years which peaked around age 26-30 years and declined from age 31 to 40 in both Districts. However, concerning the stage of pregnancy, the total number of IgG and IgM seropositivity in the study participants increased from the first trimester to the third trimester (Table 2).

Table 2: The seropositivities of anti-T. gondii $\operatorname{lgG} / \operatorname{lgM}$ among age groups and the stages of pregnancy in the two Districts

\section{Antibody concentration among participants in the Bosomtwe district}

The mean antibody levels increased up to age group 26-30 years, there was then a decrease up to age range 36-40 years (Figure 1A). There was however no statistical difference $(P>0.05)$ between the concentration of antibodies and age of participants as well as the stage of pregnancy (Figure 1A and IB). 


\section{Infection status and exposure to risk factors}

All the study participants ate vegetables with many of them (97.7\%) steaming and/cooking them before ingestion. All of them ate khebabs although there were varying responses from the study participants with regards to the types of meat used in the preparation of the khebabs. The results also showed that more than half (53.4\%) of the toxoplasmosis seropositive pregnant mothers (either $\lg G$ or $\lg M$ ) said they have been exposed to cats and its excreta. There was no significant difference between the seropositive participants who had been exposed and those who had not been exposed to any of the assessed risk factors $(P>0.05)$. No correlation between risk factors and seroprevalence of infection $(O R<1)$ was observed (Table 3)

Table 3: Relationship between Toxoplasma gondii infection and associated risk factors

\section{Discussion}

Toxoplasmosis caused by an obligate intracellular protozoan parasite, Toxoplasma gondii, is a widely distributed infection that affects humans, pets and livestock in both developing and developed countries including Ghana [22]. However, in Ghana studies that have been conducted are mainly in the southern part of the country. This has necessitated the current study in the middle belt of Ghana.

The seroprevalences of $78.1 \%$ and $75.0 \%$ recorded among the pregnant women from the Asunafo North District in the Ahafo and the Bosomtwe District from the Ashanti Region respectively are high compared to $30 \%-65 \%$ reported as the global population infection status by Ayeh-Kumi in 2010 [21]. However, it was lower when compared to previously recorded seroprevalence of $92.5 \%$ in the Greater Accra Region of Ghana by Ayi et. al., in 2009 [18].

The transmission and the subsequent seropositivity to the parasite is reported to be relatively higher in hot and humid areas such as Africa and as such prevalences are higher in some parts of the world as compared to others [23-24]. This is because the longevity of the viability of the $T$. gondii oocysts are enhanced in hot and humid conditions. In Brazil, approximately one in two people have the infection (51\%) and this shows a high seropositivity [23]. On the contrary, a moderately low prevalence of $18.9 \%$ was recorded for Finland, 28\% for Denmark and 39\% for the United States where the temperature and humidity is relatively low. It is therefore not surprising that Ghana, a tropical country with hot and humid climatic conditions, has high seroprevalence as reported in this study for the two Districts and other studies $[5,18,21]$.

There was no association ( $P>0.05)$ between seroprevalence and the various risk factors as well as demographic properties assessed in this study in both Districts. Thus, the study supported previous and recent epidemiological studies which showed that cat ownership and other risk factors of the T. gondii infection were less predictive in determining the acquisition of theinfection [25]. It has been reported that one does not necessarily have to come into contact with cat or its faeces to acquire the infection, but 
rather a higher risk for toxoplasmosisinfection is generally imposed on human communities with high exposure to cats, its faeces and/or the extensive art of lambing since free oocysts will constantly be circulating in the environment [26]. Nevertheless, the high seroprevalences reported in this study could be due to other notable risk factors such as the carrying of oocysts from faecal matter to food by flies and the drinking of contaminated water as observed in some outbreaks [27-29]. In an environment such as where the studies were conducted, one does not have to own a cat to get the infection since cat faeces are all over the environment.

Seropositivity and antibody concentration were found to increase with age until after 30 years where there was a decline. This is because as one ages, he becomes increasingly exposed to the infection as has also been reported in other studies, that the rate of the infection acquisition increased by $0.5 \%$ to $1.0 \%$ per year of age, with the total prevalent antibody level gradually increasing with age, reaching a peak of $23.7 \%$ in the active life years [30-32].

Even though higher number of participants from Asunafo North District had previously been exposed compared with Bosomtwe District, the number of ongoing infections were not different. Probably because the two districts have the similar climatic conditions even though Ghana Statistical Service in their 2010 Population and Housing Census reported that the average humid and temperature conditions in Ahafo Region is higher than that of the Ashanti Region [33].

The study also showed that there were significant differences $(P<0.001)$ in the seropositivity of anti- $T$. gondii IgGs relative to their respective anti-T. gondii IgMs in both Districts (Table 2). This showed that a high proportion of these pregnant women (99/146 in Asunafo North, 72/120 in Bosomtwe) have had previous or past exposures compared to those with recent exposures (34/146 in Asunafo North, 36/120 in Bosomtwe). The tendency of this past infection being in latency with persisting tissue cysts (bradyzoites) especially those who were seropositive for both IgG and IgM poses a high risk to the foetuses of these pregnant women since vertical transmission of the infection can occur if the mother acquires an acute infection duringpregnancy. However, an acute infection may result from either a primary (recent) infection or re-activation/re-occurrence oflatent (chronic) infection in any case of immuno-suppression. Since latency can be established in the nerve ganglia of the brain, eye and the striated muscles of the heart (tissue tropisms varies in persons) and resurface later when the immunocompetent person becomes immuno-suppressed later in life, the development of the foetuses are then at risk [5, 34-35].

From this study, all the IgG seropositive pregnant women could probably have their foetuses contract congenital toxoplasmosis in case of parasitic re-activation from the nerve ganglia of the tropic tissue where chronic stage Toxoplasma gondii tissue cysts (bradyzoites) will be released into the blood stream and be transformed into tachyzoites, which is the acute stage $T$. gondii tissue cysts to cause the infection.

It has been reported in other studies that an acute maternal infection in the first trimester of the human gestation period results in a foetal transmission rate of $10-15 \%$, rising to about $68 \%$ in the third trimester 
of the gestation period [14-16, 36]. In this study, the total number of IgG and IgM seropositivity increased from the first trimester to the third trimester (Table 2). Although, there was no statistical difference $(P>0.05)$ in the mean antibody concentration levels from trimesters one to three (Figure 1B), the babies that would be born to the anti-T. gondii IgM seropositive pregnant women are at a greater risk of contracting congenital toxoplasmosis, especially those in their first trimester. This is because the IgM seropositive pregnant women would have carried the acute infection together with the foetus in the uterus for at last 6 months before delivery and that prolongs the time span for probable foetal contraction of the infection $[7,11]$. What is not clear is whether this high seroprevalence observed would translate into clinical manifestations or not in the new borne babies. There is therefore the need for a follow up study to follow the babies to assess whether they will exhibit any clinical manifestation of the infection.

In 2008, Afonso et al., in their study that assessed the spatial distribution of soil contamination by $T$. gondii in relation to cat defaecation behaviour in urban areas reported that the extensive lambing and the improper keeping of cats as pets without sand boxes continually contaminate the soil. It was also established that the risk of infection was not related to the owning of a cat but rather being exposed to the faeces of a cat with shed oocysts [37].

Contrary to Dubey's (2004) and Afonso's (2008) studies [8, 37], all the risk factors analysed in this study showed no correlation and significance $(\mathrm{OR}<1)$ with the $T$. gondii infection status of the participating pregnant women. The difference between the $T$. gondii seropositive pregnant mothers who had been exposed to the risk factors assessed and that of the mothers unexposed in this study was statistically not significant $(P>0.05)$.

This study supported previous and recent epidemiological studies which showed that cat ownership, a high risk factor for $T$. gondii infection, was less predictive in the acquisition of the $T$. gondii infection [38]. Thus, it can be deduced that one may not necessarily have to come into contact with cat or its faeces to be infected, rather a high risk for toxoplasmosis infection is imposed on human communities with high exposure to cats and/or the extensive lambing since free oocysts will constantly be circulating in the environment [26].

Meat and vegetable consumption as well as general eating habits have also been widely reported as risk factors for T. gondii infection [2]. In Ghana and other countries, it has been reported that the infection is found in most farm animals especially in pigs, sheep and goats and thus their ingestion could lead to the infection [39-40]. However in this study, no relationship was found between meat and vegetable consumption and T. gondii infection.

\section{Conclusion}

From the study, $78 \%$ and $75 \%$ of the participants from the Asunafo and the Bosomtwe District respectively were seropositive for the anti-Toxoplasma gondii specific antibodies (IgG and IgM). There was no association between seroprevalence and the various risk factors assessed in this study. This 
study provides baseline data for future studies in the other Districts and Regions in the country to ascertain the overall seroprevalence in Ghana.

\section{List Of Abbreviations}

ANC: Antenatal care; HIV: Human immunodeficiency virus; ELISA: Enzyme linked immunosorbent assay; T. gondii: Toxoplasma gondii; IgG: Immunoglobulin G; IgM: Immunoglobulin M; SPSS: Statistical Package for Social Scientists; ANOVA; Analysis of variance.

\section{Declarations}

\section{Ethics approval and consent to participate}

All participants gave a signed informed consent to participate. Additional consent, either signed or thumbed, was obtained from parents or guardians of participants who were below 18 years. Ethical approval was obtained from the Committee on Human Research, Publications and Ethics (CHRPE), of the School of Medicine and Dentistry of the Kwame Nkrumah University of Science and Technology, Kumasi, Ghana.

\section{Consent to publish}

Not applicable.

\section{Availability of data and materials}

The datasets used and/or analyzed during the current study are available from the corresponding author on reasonable request.

\section{Competing interests}

The authors declare that they have no competing interests.

\section{Funding}

Not applicable.

\section{Authors' Contributions}


AYD, DAM and CEA designed the study. AYD and LBD reviewed the methodology. DAM and CEA performed the research and collected data from the health centers. DAM, LBD and AYD performed the analysis of the data. DAM drafted the original manuscript. AYD and LBD reviewed and edited the manuscript. All authors read and approved the final manuscript.

\section{Acknowledgements}

We are grateful to all Filariasis staff of the Kumasi Centre for Collaborative Research in Tropical Medicine (K. C. C.R), most especially Dr. Jubin Osei-Mensah and Mr. Yusif Mubarik. We also acknowledge the laboratory and the antenatal department of the St. Michael's Catholic Missionary Hospital and the Goaso Municipal Hospital staff for allowing us to use their facility, notably Mr. Gilbert Osei. The study also appreciates Dr. Dompreh of the Serology unit, Komfo Anokye Teaching Hospital (KATH) for his immense support and academic contribution.

\section{References}

1. Dubey JP. Re-examination of resistance of Toxoplasma gondii tachyzoites and bradyzoites to pepsin and trypsin digestion. Parasitology. 1998 Jan;116(1):43-50.

2. Dubey JP, Beattie CP. Toxoplasmosis of animals and man. CRC Press, Inc.; 1988.

3. ROBERT L, JANovY J. JR. (2000): Foundations of Parasitology.

4. Kwofie KD. Risk of Mother-To-Child Transmission of Toxoplasma Gondii Infection among Pregnant Women in the Greater Accra Region (Doctoral dissertation). 2012.

5. Ayi I, Sowah AO, Blay EA, Suzuki T, Ohta N, Ayeh-Kumi PF. Toxoplasma gondii infections among pregnant women, children and HIV-seropositive persons in Accra, Ghana. Tropical medicine and health. 2016 Dec;44(1):17.

6. Giannoulis C, Zournatzi B, Giomisi A, Diza E, Tzafettas I. Toxoplasmosis during pregnancy: a case report and review of the literature. Hippokratia. 2008 Jul;12(3):139.

7. Stepick-Biek P, Thulliez P, Edwards ME. Fungal and protozoan infections. Neonatal-perinatal medicine, diseases of fetus and infant (7th ed.). St Louis: Mosby. 2002.

8. Dubey JP. Toxoplasmosis-a waterborne zoonosis. Veterinary parasitology. 2004 Dec 9;126(12):57-72.

9. Galván-Ramírez MD, Guillén-Vargas C, Saavedra-Durán R, Islas-Rodríguez A. Analysis of Toxoplasma gondii antigens with sera from toxoplasmosis patients. Revista da Sociedade Brasileira de Medicina Tropical. 1998 Jun;31(3):271-7.

10. Berger F, Goulet V, Le Strat $Y$, Desenclos JC. Toxoplasmosis among pregnant women in France: risk factors and change of prevalence between 1995 and 2003. Revue d'epidemiologie et de sante publique. 2009 Aug 1;57(4):241-8. 
11. Centers for Disease Control, Prevention (US). Epidemiology Program Office. MMWR.:

Recommendations and Reports. US Department of Health and Human Services, Public Health Service, Centers for Disease Control, Epidemiology Program Office; 2000.

12. Daffos F, Forestier F, Capella-Pavlovsky M, Thulliez P, Aufrant C, Valenti D, Cox WL. Prenatal management of 746 pregnancies at risk for congenital toxoplasmosis. New England Journal of Medicine. 1988 Feb 4;318(5):271-5.

13. Vogel N, Kirisits M, Michael E, Bach H, Hostetter M, Boyer K, Simpson R, Holfels E, Hopkins J, Mack D, Mets MB. Congenital toxoplasmosis transmitted from an immunologically competent mother infected before conception. Clinical infectious diseases. 1996 Nov 1;23(5):1055-60.

14. Foulon W, Villena I, Stray-Pedersen B, Decoster A, Lappalainen M, Pinon JM, Jenum PA, Hedman K, Naessens A. Treatment of toxoplasmosis during pregnancy: a multicenter study of impact on fetal transmission and children's sequelae at age 1 year. American journal of obstetrics and gynecology. 1999 Feb 1;180(2):410-5.

15. Dunn D, Wallon M, Peyron F, Petersen E, Peckham C, Gilbert R. Mother-to-child transmission of toxoplasmosis: risk estimates for clinical counselling. The Lancet. 1999 May 29;353(9167):182933.

16. Holliman RE. Congenital toxoplasmosis: prevention, screening and treatment. journal of Hospital Infection. 1995 Jun 1;30:179-90.

17. Alpert JJ. Infectious diseases of the fetus and newborn infant. Remington JS, Klein JO, editors. Philadelphia: Saunders; 1976.

18. Ayi I, Edu S, Apea-Kubi KA, Boamah D, Bosompem KM, Edoh D. Sero-epidemiology of toxoplasmosis amongst pregnant women in the greater Accra region of Ghana. Ghana medical journal. 2009;43(3).

19. Guerina NG, Hsu HW, Meissner HC, Maguire JH, Lynfield R, Stechenberg B, Abroms I, Pasternack MS, Hoff R, Eaton RB, Grady GF. Neonatal serologic screening and early treatment for congenital Toxoplasma gondii infection. New England Journal of Medicine. 1994 Jun 30;330(26):1858-63.

20. Anteson RK, Sekimoto S, Furukawa S, Takao Y, Nyanotor MA. Studies on toxoplasmosis in Ghana I. The prevalence of toxoplasmosis as measured by the haemagglutination (Eiken) test. Ghana Med J. 1978;17:147-9.

21. Ayeh-Kumi PF, Opoku AG, Kwakye-Nuako G, Dayie NT, Asmah RH, Nkrumah NO, Lartey M, Sagoe A, Attipoe MI, Osafo KA, Kretchy JP. Sero-prevalence of toxoplasmosis among patients visiting the Korle-Bu Teaching Hospital, Accra, Ghana. Reviews in Infection. 2010;1(3):147-50.

22. Saadatnia G, Golkar M. A review on human toxoplasmosis. Scandinavian journal of infectious diseases. 2012 Nov 1;44(11):805-14.

23. Feldman HA. Toxoplasmosis: an overview. Bulletin of the New York Academy of Medicine. 1974 Feb;50(2):110.

24. Meerburg, BG, and kijlstra A. Changing climate- changing pathogens: Toxoplasma gondii in NorthWestern Europe.Parasitology research. 2009 Jun 1;105(1):17-24. 
25. Jones JE, Lopez A, Wilson M. Congenital toxoplasmosis. American family physician. 2003 May 15;67(10):2131-46.

26. McAllister MM. A decade of discoveries in veterinary protozoology changes our concept of "subclinical" toxoplasmosis. Veterinary parasitology. 2005 Sep 30;132(3-4):241-7.

27. Wallace GD. Experimental transmission of Toxoplasma gondii by filth-flies. The American journal of tropical medicine and hygiene. 1971 May 1;20(3):411-3.

28. Isaac-Renton J, Bowie WR, King A, Irwin GS, Ong CS, Fung CP, Shokeir MO, Dubey 0. Detection of Toxoplasma gondii oocysts in drinking water. Applied and environmental microbiology. 1998 Jun 1;64(6):2278-80.

29. Bahia-Oliveira LM, Jones JL, Azevedo-Silva J, Alves CC, Oréfice F, Addiss DG. Highly endemic, waterborne toxoplasmosis in north Rio de Janeiro state, Brazil. Emerging infectious diseases. 2003 Jan;9(1):55.

30. Krick JA, Remington JS. Toxoplasmosis in the adult-an overview. New England Journal of Medicine. 1978 Mar 9;298(10):550-3.

31. Al Hamdani MM, Mahdi NK. Toxoplasmosis among women with habitual abortion.

32. Nester EW, Anderson DG, Roberts CE, Pearsall NN, Nester MT. Microorganisms in food and beverage production-alcoholic fermentation by yeast. Microbiology-A Human Perspective. 2004:151-3.

33. Ghana. Statistical Service. 2010 Population \& Housing Census: National Analytical Report. Ghana Statistical Service; 2013.

34. Luft BJ, Remington JS. Toxoplasmic encephalitis in AIDS. Clinical Infectious Diseases. 1992 Aug 1;15(2):211-22.

35. Israelski DM. Toxoplasmosis in the non-AIDS immunocompromised host. Curr Clin Topics in infectious diseases. 1993;13:322-56.

36. Thulliez PH, Daffos FE, Forestier FR. Diagnosis of Toxoplasma infection in the pregnant woman and the unborn child: current problems. Scandinavian journal of infectious diseases supplement. 1992 Jan 1:18-22.

37. Afonso E., Lemoine M., Poulle M., Ravat M., Romand S., Thulliez P., Villena I, Aubert D., Rabilloud M., Richie B., (2008). Spatial distribution of soil contamination by Toxoplasma gondii in relation to cat defecation behaviour in urban area. Int J. Parasitol 38(8-9), 1017-1023.

38. Jeffrey, J., Lopez, A. and Wilson, M. (2003). Congenital Toxoplasmosis. Journal of the American Academy of Family Physician 8, 2145-2146.

39. Arko-Mensah, J., Bosompem, K. M., Canacoo, J., Wastling, M. and Akanmori, B. D. (2000). The Seroprevalence of Toxoplasmosis in Pigs in Ghana, Acta Tropica, 76 (1), 27-31.

40. Van der Puije, W. N. A., Bosompem, K. M., Canacoo, E. A., Wastling, J. M. and Akanmori, B. D. (2000). The Prevalence of Anti-Toxoplasma gondii Antibodies in Ghanaian sheep and goats. Acta Tropica, 76(1), 15-20. 


\section{Tables}

Table 1: Age and stage of pregnancy distribution of study participants in the two Districts

\begin{tabular}{cccc}
\hline CHARACTERISTIC & \multicolumn{2}{c}{ DISTRICTS } & P-VALUE \\
\cline { 2 - 3 } & ASUNAFO & BOSOMTWE & \\
\hline Age group (years) & Frequency (\%) & Frequency (\%) & \\
$16-20$ & $25(17.1)$ & $24(20.0)$ & 0.414 \\
$21-25$ & $55(37.7)$ & $42(35.0)$ & 0.446 \\
$26-30$ & $28(19.2)$ & $30(25.0)$ & 0.112 \\
$31-35$ & $21(14.4)$ & $18(15.0)$ & 0.865 \\
$36-40$ & $17(11.6)$ & $6(5.0)$ & 0.073 \\
Stage of pregnancy & & & \\
First trimester & $36(24.7)$ & $23(19.17)$ & 0.128 \\
Second trimester & $61(41.8)$ & $42(35.0)$ & 0.066 \\
Third trimester & $49(33.6)$ & $55(45.83)$ & 0.002 \\
\hline
\end{tabular}

Table 2: The seropositivities of anti-T. gondii lgG/lgM among age groups and the stages of pregnancy in the two Districts 


\begin{tabular}{|c|c|c|c|c|c|c|c|c|}
\hline \multirow{2}{*}{$\begin{array}{l}\text { Charac- } \\
\text { teristic }\end{array}$} & \multicolumn{8}{|c|}{ ANTIBODY SEROPOSITIVITY } \\
\hline & \multicolumn{4}{|c|}{ ASUNAFO NORTH } & \multicolumn{3}{|c|}{ BOSOMTWE } & TOTAL \\
\hline & $\begin{array}{c}\lg \mathbf{G} N \\
(\%)\end{array}$ & $\begin{array}{c}\operatorname{lgM} N \\
(\%)\end{array}$ & $\begin{array}{l}\text { Both IgG \& } \\
\operatorname{lgM} N(\%)\end{array}$ & $\begin{array}{c}\operatorname{IgGN} \\
(\%)\end{array}$ & $\begin{array}{c}\operatorname{lgM} N \\
(\%)\end{array}$ & $\begin{array}{c}\text { Both } \\
\lg G\end{array}$ & $\lg G$ & $\operatorname{lgM}$ \\
\hline & & & & & & 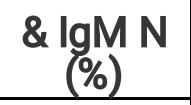 & & \\
\hline $16-20$ & 10 & 2 & $3(15.8)$ & 15 & 4 & $2(11.1)$ & 30 & 11 \\
\hline $21-25$ & $\begin{array}{c}27 \\
(338)\end{array}$ & $\begin{array}{c}9 \\
(6 \cap 0)\end{array}$ & $8(42.1)$ & $\begin{array}{l}12 \\
(22)\end{array}$ & $\begin{array}{c}6 \\
(333)\end{array}$ & $\begin{array}{c}12 \\
(666)\end{array}$ & 59 & 35 \\
\hline $26-30$ & $\begin{array}{c}23 \\
(28.7)\end{array}$ & $1(6.7)$ & $1(5.3)$ & $\begin{array}{c}17 \\
(31.5)\end{array}$ & $\begin{array}{c}(33.3) \\
4 \\
(22.2)\end{array}$ & $1(5.6)$ & 42 & 7 \\
\hline $31-35$ & $\begin{array}{c}12 \\
(15.0)\end{array}$ & $\begin{array}{c}2 \\
(13.3)\end{array}$ & $4(21.0)$ & $\begin{array}{c}6 \\
(11.1)\end{array}$ & $\begin{array}{c}3 \\
(16.7)\end{array}$ & $2(11.1)$ & 24 & 11 \\
\hline $36-40$ & 8 & $1(6.7)$ & $3(15.8)$ & $4(7.4)$ & $1(5.6)$ & $1(5.6)$ & 16 & 6 \\
\hline $\begin{array}{l}\text { Total } \\
\text { Stage of } \\
\text { Pregnancy }\end{array}$ & $\begin{array}{c}80 \\
(100)\end{array}$ & $\begin{array}{c}15 \\
(100)\end{array}$ & $19(100)$ & $\begin{array}{c}54 \\
(100)\end{array}$ & $\begin{array}{c}18 \\
(100)\end{array}$ & $18(100)$ & 171 & 70 \\
\hline $1^{\mathrm{ST}}$ trim. & $\begin{array}{c}22 \\
(27.5)\end{array}$ & $\begin{array}{c}5 \\
(33.3)\end{array}$ & $5(26.3)$ & $\begin{array}{c}11 \\
(20.4)\end{array}$ & $\begin{array}{c}4 \\
(22.2)\end{array}$ & $2(11.1)$ & 40 & 16 \\
\hline $2^{\mathrm{ND}}$ trim. & $\begin{array}{c}32 \\
(40.0)\end{array}$ & $\begin{array}{c}9 \\
(60.0)\end{array}$ & $6(31.6)$ & $\begin{array}{c}18 \\
(33.3)\end{array}$ & $\begin{array}{c}6 \\
(33.3)\end{array}$ & 6 (33.3) & 62 & 27 \\
\hline $3^{\mathrm{RD}}$ trim. & $\begin{array}{c}26 \\
(32.5)\end{array}$ & $1(6.7)$ & $8(42.1)$ & $\begin{array}{c}25 \\
(46.3)\end{array}$ & $\begin{array}{c}8 \\
(44.5)\end{array}$ & $\begin{array}{c}10 \\
(55.6)\end{array}$ & 69 & 27 \\
\hline Total & $\begin{array}{c}80 \\
(100)\end{array}$ & $\begin{array}{c}15 \\
(100)\end{array}$ & 19 (100) & $\begin{array}{c}54 \\
(100)\end{array}$ & $\begin{array}{c}18 \\
(100)\end{array}$ & $18(100)$ & 171 & 70 \\
\hline
\end{tabular}

Table 3: Relationship between Toxoplasma gondii infection and associated risk factors

\begin{tabular}{ccccc}
\hline \multirow{2}{*}{ Risk factor } & \multicolumn{2}{c}{ Seropositivity } & P-value & Odd ratio \\
\cline { 2 - 3 } & \multicolumn{2}{c}{ Exposed (\%) } & Unexposed (\%) & \\
\hline \\
Possession or exposure to cats & $109(53.4)$ & $95(46.6)$ & 0.066 & 0.416 \\
Exposure to cat faeces & $109(53.4)$ & $95(46.6)$ & 0.066 & 0.416 \\
Intake of vegetables & $104(51)$ & $100(49)$ & 0.571 & 0.133 \\
Intake of meat & $98(48)$ & $106(52)$ & 0.264 & 0.301 \\
Availability of sand box & $112(54.9)$ & $92(45.1)$ & 0.110 & 0.391 \\
The art of lambing & $94(46)$ & $110(54)$ & 0.115 & 0.424 \\
Handing of raw/uncooked meat & $114(55.9)$ & $90(44.1)$ & 0.121 & 0.535 \\
\hline
\end{tabular}


Figures

Figure $1 \mathrm{~A}$.

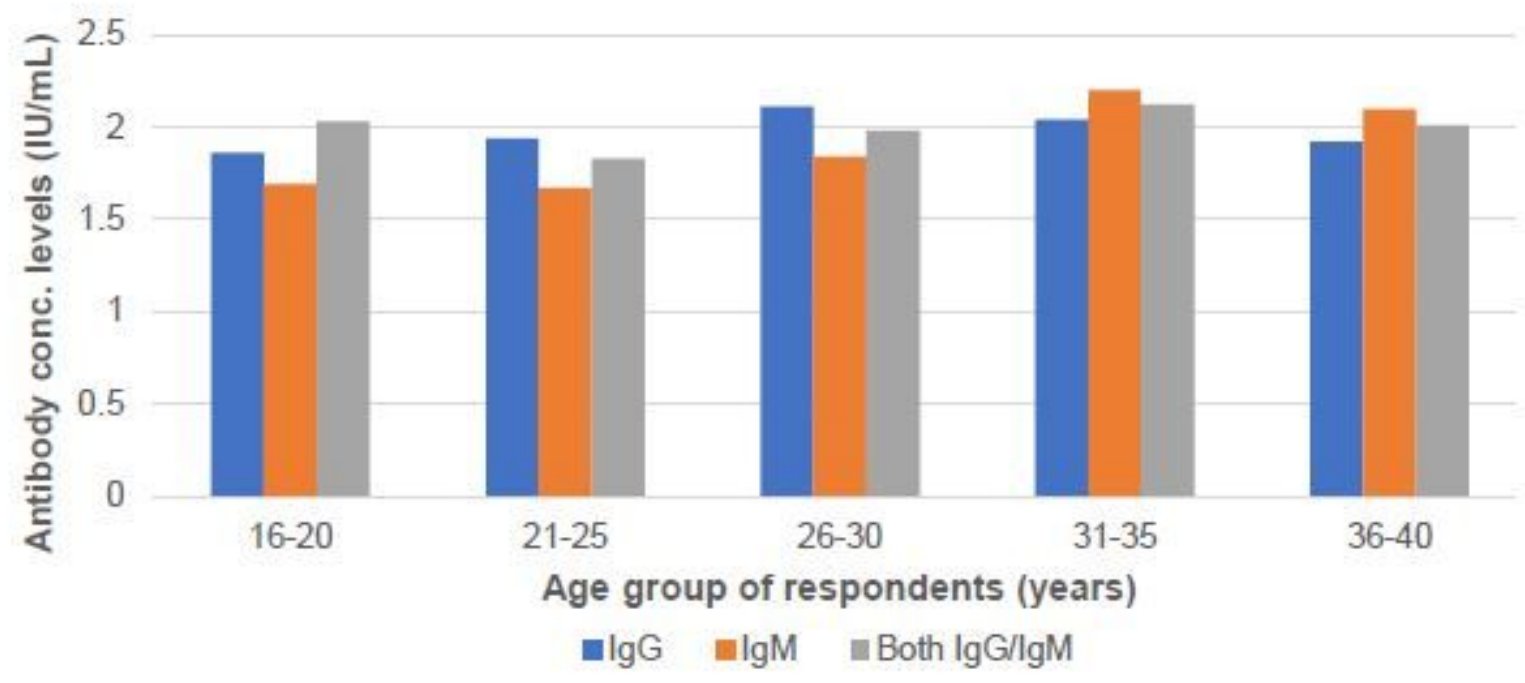

Figure 1B.

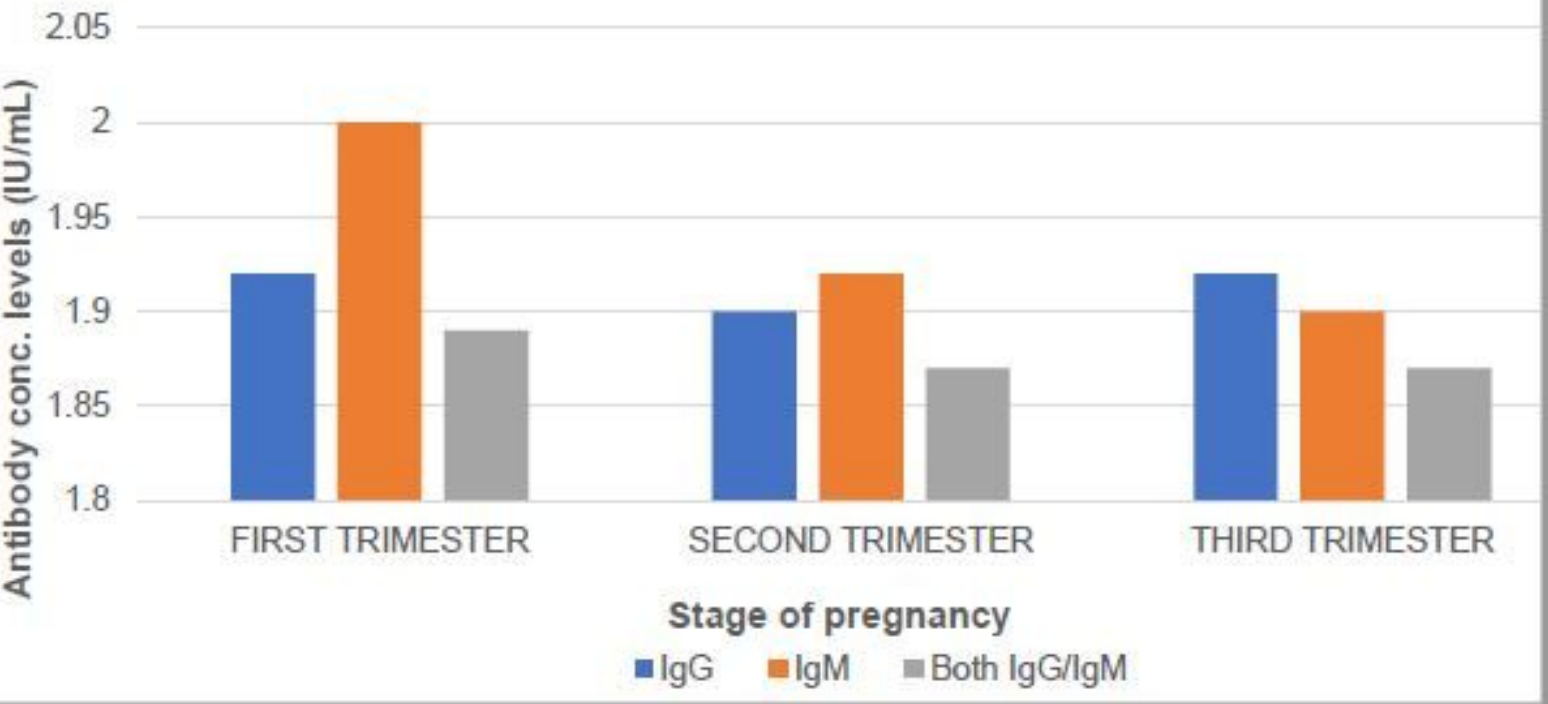

Figure 1 
Mean anti-T. gondii antibody levels among age groups (A) and the stage of pregnancy (B). 